\title{
Examining the Psychometric Properties of the Behavioral Regulation in Exercise Questionnaire
}

\author{
Philip M. Wilson, Wendy M. Rodgers, and Shawn N. Fraser \\ Faculty of Physical Education \& Recreation \\ University of Alberta
}

\begin{abstract}
The purpose of this study was to examine select psychometric properties of the Behavioral Regulation in Exercise Questionnaire (BREQ; Mullen, Markland, \& Ingledew, 1997). To accomplish this aim, data were gathered in 2 phases to evaluate the BREQ's factorial composition and structure and the relation between the BREQ, need satisfaction, exercise behavior, and relevant motivational constructs. Participants completed measures assessing psychological need satisfaction, optimism, perceived behavioral control, exercise behavior, and the BREQ. Phase 1 results supported the original 4-factor measurement model and a simplex model of structural relations between latent BREQ constructs suggested within self-determination theory (Deci \& Ryan, 1985), and results supported the positive relations between more self-determined motives and greater psychological need satisfaction and frequent exercise behavior. Phase 2 results provided further construct validity evidence for the BREQ by linking subscale scores with greater perceived behavioral control in a manner consistent with theory (Deci \& Ryan, 1985). Collectively, these results further support the construct validity of the BREQ and lend credence to the notion of measuring exercise motivation from a multidimensional perspective using self-determination theory as a guiding framework in the exercise domain.
\end{abstract}

Key words: self-determination theory, exercise adherence, psychometric properties

Understanding why people exercise is a central focus of motivational research in both health and exercise psychology (Dishman, 1994). One theoretical approach to the study of motivation that has received considerable attention recently in health promotion domains is self-determination theory (SDT; Deci \& Ryan, 1985; Ryan \&

Requests for reprints should be sent to Philip M. Wilson, Faculty of Physical Education \& Recreation, E-401 Van Vliet Centre, University of Alberta, Edmonton, Alberta, T6G 2H9, Canada. E-mail: pmwilson@ualberta.ca 
Deci, 2000). This motivational framework is appealing given that SDT specifies the conditions under which various motives develop and the resulting consequences of endorsing different motives within a given context. According to SDT, the degree to which a social context satisfies a person's psychological needs for competence, autonomy, and relatedness determines the quality of motivation exhibited. Furthermore, motives underpinned by greater self-determination are associated with more positive consequences such as task engagement, behavioral persistence, and enhanced psychological well-being (Deci \& Ryan, 1985; Ryan \& Deci, 2000). Following Deci and Ryan's (1985) seminal theorizing, the major premises of SDT have been applied and supported in different contexts including education (Vallerand, Fortier, \& Guay, 1997), leisure (Losier, Bourque, \& Vallerand, 1993), sport (Pelletier et al., 1995), politics (Losier \& Koestner, 1999), and health promotion (Williams, Freedman, \& Deci, 1998).

Central to SDT is the notion that extrinsic motives (called regulations) reside along a continuum underpinned by different degrees of self-determination that range from highly controlling to volitionally endorsed (Deci \& Ryan, 1985; Ryan \& Deci, 2000). In the exercise domain, external regulation involves exercising to appease some external demand (e.g., "I exercise because my friends and family say I should") and conceptually is the least self-determined form of extrinsic motivation. Introjected regulation, the next stage along the motivational continuum, involves feeling coerced to exercise to avoid negative emotions or to support conditional self-worth (e.g., "I feel guilty when I don't exercise"). Following introjection, identified regulation refers to exercising because one values the important benefits associated with being physically active but still finds the behavior itself unenjoyable (e.g., "I value the benefits of exercise"). ${ }^{1}$ The last point on the self-determination continuum is intrinsic regulation, which involves exercising for no separable consequence other than the enjoyment and satisfaction associated with the behavior itself (e.g., "I exercise because it is fun"). ${ }^{2}$

\footnotetext{
${ }^{1}$ In the broader context of self-determination theory (Deci \& Ryan, 1985; Ryan \& Deci, 2000), there is another form of extrinsic motivation termed integrated regulation. Integrated regulation occurs "when identified regulations have been fully assimilated to the self" (Ryan \& Deci, 2000, p. 62) and conceptually represents a point along the motivational continuum between identified and intrinsic regulation. The BREQ, however, does not include a subscale assessing this facet of the motivational continuum.

${ }^{2}$ The notion of intrinsic regulation has been conceptualized within the BREQ in a manner consistent with Deci and Ryan's (1985) theorizing. Recent research (Li, 1999) and commentary (Vallerand, 1999) propose a multidimensional conception of intrinsic motivation. Although this notion is appealing, these contentions have yet to be systematically evaluated in the physical domain and represent an extension of SDT's multidimensional extrinsic motivation continuum. Given that our major purpose in this article was to examine the psychometric qualities of the BREQ, which uses a single scale to measure intrinsic motivation that is consistent with SDT, we do not further discuss the multidimensionality of intrinsic motivation here. The interested reader is referred to Vallerand $(1997,1999)$ for a conceptual discussion and $\mathrm{Li}$ and Harmer (1996) for empirical evidence that questions the measurement of multidimensional forms of intrinsic motivation in the physical activity domain.
} 
Despite SDT's appeal, our understanding of the full range of propositions outlined by the theory in exercise contexts remains rudimentary (Vallerand, 1999). One factor limiting an examination of SDT propositions in the exercise domain has been the absence of psychometrically sound instruments that adequately measure the motivational continuum. In this regard, Mullen and colleagues (Mullen, Markland, \& Ingledew, 1997; Mullen \& Markland, 1997) developed the Behavioral Regulation in Exercise Questionnaire (BREQ) based on responses from community sports center attendees (mean age $=29.98, S D=9.18,68 \%$ female), as an initial attempt to quantify the motivational continuum in the exercise domain. ${ }^{3}$

In their original development and validation article, Mullen et al. (1997) used confirmatory factor analytic procedures to develop and support the presence of a four-factor measurement model that was consistent with the overall framework of SDT and invariant across gender. The subscales comprising the BREQ represent a graded conceptualization of exercise motivation that are consistent with SDT and were labeled accordingly (i.e., external, introjected, identified, and intrinsic regulation). Mullen and Markland (1997) provided additional support for the scale by demonstrating that scores on the BREQ discriminated between people at different stages of exercise adoption. Specifically, people in the action and maintenance stages of exercise adoption reported exercising for more identified and intrinsic reasons than did people at the pre-preparation and preparation stages.

Although current evidence supports the factorial and discriminant validity of the BREQ, construct validation is an ongoing endeavor that typically requires the collection of evidence from multiple sources and samples to determine the psychometric merit of the instrument (Messick, 1995). Messick argued that construct validity essentially must be evaluated in terms of the mosaic of evidence that imbues a person's test scores with meaning. Currently, the evidence supporting the psychometric properties of the BREQ is encouraging yet limited to a small number of studies that have yet to link the BREQ with either the need satisfaction constructs proposed within SDT or other motivational constructs. Because the BREQ is a new instrument that has been used in few studies (Mullen \& Markland, 1997; Mullen et al., 1997), additional research addressing the BREQ's psychometric properties is warranted to determine the suitability of the scale for addressing theoretical propositions. Consequently, this study was designed to examine select psychometric properties of the BREQ to determine the adequacy of the scale for

\footnotetext{
${ }^{3}$ Similar measurement development research has now produced both the Sport Motivation Scale (Pelletier et al., 1995) and the Exercise Motivation Scale (Li, 1999). The Sport Motivation Scale and Exercise Motivation Scale represent further attempts to capture the motivational continuum in different physical activity contexts. However, both scales also can be considered as extensions of SDT that include propositions forwarded under Vallerand's (1997) hierarchical model of motivation. Central to this model is the multidimensionality of intrinsic motivation, an extension of SDT's notion of the motivational continuum to include multidimensional intrinsic regulation of behavior.
} 
conducting research in exercise contexts based on the propositions embedded within SDT.

Because only one study to date has evaluated the factorial integrity of the BREQ (Mullen et al., 1997), this study was designed first to test the factorial composition and structure of the BREQ in a naturalistic exercise setting. The factor structure and composition of the BREQ were tested using confirmatory factor analysis (CFA) procedures, and a simplex model examining measurement of the SDT motivational continuum using the BREQ was tested via structural equation modeling (SEM). The second purpose was to extend the construct validity evidence of the scale by linking BREQ scores with other theoretically relevant constructs embedded within the framework of SDT. To accomplish this purpose, a nomological net (Cronbach \& Meehl, 1955) suggested by SDT was examined by linking scores on the BREQ with the psychological need satisfaction constructs (competence, autonomy, relatedness) proposed to underpin motivational development and an important motivational consequence (exercise behavior). The third purpose was to link the BREQ with motivational constructs that previous researchers suggested exert a positive motivational influence on exercise behavior (Courneya, Nigg, \& Estabrooks, 1998; Kavussanu \& McAuley, 1995). Given that the BREQ was developed under assumptions embedded within SDT, it seems reasonable to suggest that BREQ subscales should be positively related to other motivational constructs that have been linked with more frequent exercise behavior. These purposes were addressed by two separate phases in this study.

\section{PHASE 1}

The purpose of Phase 1 was to (a) test the proposed factor structure and composition of the BREQ, (b) examine the ability of a simplex model based on SDT's propositions to account for the observed BREQ data, and (c) examine the relation of the BREQ with both psychological need satisfaction constructs and exercise behavior. SDT posits that motives are underpinned by varying degrees of self-determination, such that adjacent constructs along the motivational continuum will be more strongly associated with one another than with distal constructs (Deci \& Ryan, 1985; Ryan \& Deci, 2000). In line with this proposition, it was hypothesized that (a) the four-factor model would adequately account for the observed data, (b) a simplex structure of relations underpinning BREQ scores would be supported, and (c) more self-determined exercise regulations would be positively associated with greater psychological need satisfaction. SDT also contends that the consequences of endorsing different motives vary, whereby more self-determined regulations promote favorable patterns of task persistence and psychological well-being. Drawing on this theoretical premise, we hypothesized that self-determined exercise regulations (identified and intrinsic) would be more positively correlated with exercise behavior. 


\section{Method}

Participants. Participants ( $N=500,81.2 \%$ female; males' mean age $=33.63$, $S D=14.37$; females' mean age $=28.43, S D=12.12$ ) were predominantly students and staff enrolled in university-based exercise classes emphasizing cardiovascular conditioning (e.g., aerobics, cross-training) as the primary mode of exercise. Participants were enrolled in group-based exercise classes that met twice per week under the leadership of a qualified exercise instructor. Each exercise class lasted for $55 \mathrm{~min}$ and was conducted at a moderate intensity level recently advocated as a dosage sufficient to develop and maintain cardiorespiratory fitness in healthy adults (Pollock et al., 1998). Participants indicated that they were quite active (weekly metabolic equivalents: $M=44.48, S D=30.92$ ) based on responses to the Leisure Time Exercise Questionnaire (Godin \& Shepherd, 1985) and reported body mass index values $\left(M=26.01 \mathrm{~kg} / \mathrm{m}^{2}, S D=11.19 \mathrm{~kg} / \mathrm{m}^{2}\right)$ that marginally exceeded the desired healthy range for adults (Kerney, 1995).

\section{Measures}

BREQ. Participants completed the BREQ (Mullen et al., 1997), a 15-item self-report measure assessing the reasons why people exercise (see Table 1). The BREQ operationalizes exercise motivation along a graded self-determination continuum and includes scales assessing external, introjected, identified, and intrinsic regulations. Following the stem, "Why do you exercise?" participants respond to each item on a 5-point Likert scale ranging from 1 (not true for me) to 5 (very true for me). Previous researchers have suggested that the BREQ is reliable (subscale Cronbach's range from .76 to .90; Mullen et al.) and valid in terms of predicting stage of exercise behavior (Mullen \& Markland, 1997).

Psychological need satisfaction. Psychological need satisfaction was measured by using 3 single-item indicators to assess perceived competence ("feeling competent and capable in the exercises I attempt"), autonomy ("feeling autonomous and choiceful in the exercises I do"), and relatedness ("feeling related and connected to the people I exercise with"). Sheldon and Elliot (1999) supported the validity of these items by demonstrating that longitudinal need satisfaction predicts enhanced psychological well-being in university students. Following the stem, "To what extent do you typically have these experiences in your exercise classes?" participants responded to each item on a scale ranging from 1 (very little) to 7 (very much). Although the use of such indicators has been questioned, recent evidence suggests that single-items demonstrating suitable distributional properties and adequately representing the focal construct of interest can be as good (or as poor) as 
multi-item indicators (Gardner, Cummings, Dunham, \& Pierce, 1998). Given that the items were developed within the framework of SDT for the purpose of testing theoretical propositions and demonstrated satisfactory distributional properties in this sample, their inclusion in this study appears warranted.

Leisure Time Exercise Questionnaire (LTEQ). Participants completed the LTEQ (Godin \& Shepherd, 1985), a three-item self-report measure of exercise behavior that assesses the frequency of mild, moderate, and strenuous exercise done for at least $20 \mathrm{~min}$ per session during a typical week. A total exercise score can be calculated by weighting, then summing, each frequency dimension by its associated metabolic equivalent value (a unit representing the metabolic equivalent of physical activity in multiples of resting oxygen consumption) by using the following equation: (strenuous $\times 9)+($ moderate $\times 5)+($ mild $\times 3)$. Previous researchers have demonstrated that the LTEQ is easy to understand, reliable (test-retest $r$ s over 1 month $=.24-.86$ ), and valid on the basis of demonstrating positive relations with objective indexes of exercise behavior including physical activity monitors and maximal fitness test scores (Jacobs, Ainsworth, Hartman, \& Leon, 1993). Individual items representing mild, moderate, and strenuous exercise were weighted by their metabolic equivalents for use in Phase 1 analyses.

\section{Procedures and Analyses}

During the second week of a regularly scheduled exercise class, participants were approached by one of the investigators and invited to participate in a study examining reasons why people exercise. Each participant gave informed consent before completing the questionnaires that were subsequently returned to the researchers.

Data analysis proceeded in four stages. First, the latent factor structure and composition of the BREQ were tested with CFA procedures by using Arbuckle's (1997) AMOS program. Second, a simplex model was tested using the SEM procedures advocated by Li and Harmer (1996). Third, internal consistency estimates (coefficient $\alpha$; Cronbach, 1951) and descriptive statistics were calculated for all study variables. Finally, bivariate correlations were computed between the BREQ subscales, psychological need satisfaction constructs (competence, autonomy, and relatedness), and exercise behavior.

Model fit criteria. Based on recent recommendations (Hoyle \& Panter, 1995; Kelloway, 1998), a number of indexes were used to evaluate model fit in both the CFA and SEM analyses. Type 2 indexes were used to estimate the improvement in model fit per degree of freedom between the target and baseline models, and 
Type 3 indexes were examined to compare the relative lack of fit between competing models. The Incremental Fit Index (IFI), comparative fit index (CFI), and Normed Fit Index (NFI) were chosen as the preferred Type 2 and Type 3 indexes given the small sample size used in this study (West, Finch, \& Curran, 1995). The root mean square error of approximation (RMSEA) and the standardized root mean square residual (SRMSR) also were examined to assess the discrepancy between the implied and observed correlation matrixes. In the CFA, individual items were loaded exclusively on relevant latent factors, factors were allowed to correlate, uniqueness was not free to correlate, and the variance of each latent factor was fixed at 1.0. Although there is some dispute regarding the criteria for acceptable model fit and the behavior of fit indexes under various conditions (Thompson, 2000), it is generally accepted that values greater than .90 (CFI, IFI, NFI) and closer to zero but not greater than .10 (RMSEA, SRMSR) suggest that the fit of a model is tenable.

\section{Results}

Descriptive statistics. The distributional properties of each BREQ item were examined before the CFA and indicated that the observed data did not meet the assumptions of either univariate (see Table 1) or multivariate (Mardia's normalized estimate $=40.98$ ) normality. Although alternative estimation procedures have been suggested for nonnormal data, they typically require large sample sizes (Hu \& Bentler, 1995) and have been associated with less desirable estimates of model fit when the sample size is small (Maruyama, 1998). West et al. (1995) recommended the use of normal theory estimators with the CFI and IFI when the sample is small. Therefore, we used maximum likelihood estimation procedures for these analyses.

$B R E Q$ factor structure. An examination of the model fit indexes suggested that the proposed four-factor measurement model (see Table 1) appeared tenable $(\mathrm{Q}$ $\left[\chi^{2} / d f\right]=3.87, \mathrm{NFI}=.91, \mathrm{IFI}=.92, \mathrm{CFI}=.92, \mathrm{SRMSR}=.04, \mathrm{RMSEA}=.09,90 \% \mathrm{con}-$ fidence interval $[\mathrm{CI}]=.07-.10)$. The standardized factor loadings revealed moderate to strong $\left(M_{\lambda}=.73\right.$, range $\left.=.46-.94\right)$ relations between the four latent factors and BREQ items, whereas the pattern of interfactor correlations inferred the presence of a simplex structure suggesting that the BREQ measures related but discrete aspects of exercise motives. The exception is the sizable interfactor correlation between identified and intrinsic regulation, which suggests a considerable degree of overlap between these two scales.

Modification indexes and standardized residuals were examined to determine if model fit could be improved without compromising the theoretical underpinnings of the BREQ. The standardized residuals indicated one item (external regulation 
TABLE 1

CFA Solution for the Behavioral Regulation in Exercise Questionnaire

\begin{tabular}{|c|c|c|c|c|c|c|}
\hline Item & BREQ Factors and Subscale Items & $M$ & $S D$ & Skewness & Kurtosis & $\lambda$ \\
\hline \multicolumn{7}{|l|}{ External regulation } \\
\hline 1. & Because other people say I should & 1.52 & 0.87 & 1.79 & 2.87 & .79 \\
\hline 5. & $\begin{array}{l}\text { Because my friends/family/spouse } \\
\text { say I should }\end{array}$ & 1.54 & 0.83 & 1.69 & 2.74 & .89 \\
\hline 9. & $\begin{array}{l}\text { Because others will not be pleased } \\
\text { with me if I don't }\end{array}$ & 1.20 & 0.54 & 3.28 & 11.82 & .46 \\
\hline 13. & $\begin{array}{l}\text { I feel under pressure from } \\
\text { friends/family to exercise }\end{array}$ & 1.38 & 0.75 & 2.32 & 5.74 & .72 \\
\hline \multicolumn{7}{|l|}{$\begin{array}{l}\text { Introjected regulation } \\
\quad(\text { Cronbach's } \alpha=.74)\end{array}$} \\
\hline 2. & I feel guilty when I don't exercise & 3.06 & 1.18 & -0.08 & -0.92 & .79 \\
\hline 6. & $\begin{array}{l}\text { I feel ashamed when I miss an } \\
\text { exercise session }\end{array}$ & 2.28 & 1.18 & 0.59 & -0.62 & .68 \\
\hline 10. & $\begin{array}{l}\text { I feel a failure when I haven't } \\
\text { exercised in a while }\end{array}$ & 2.18 & 1.12 & 0.78 & -0.20 & .58 \\
\hline \multicolumn{7}{|l|}{$\begin{array}{l}\text { Identified regulation } \\
\quad(\text { Cronbach's } \alpha=.79)\end{array}$} \\
\hline 3. & I value the benefits of exercise & 4.63 & 0.69 & -2.39 & 7.12 & .66 \\
\hline 7. & $\begin{array}{l}\text { It's important to me to exercise } \\
\text { regularly }\end{array}$ & 4.15 & 1.02 & -1.12 & 0.59 & .85 \\
\hline 11. & $\begin{array}{l}\text { Its important to make an effort to } \\
\text { exercise regularly }\end{array}$ & 4.45 & 0.77 & -1.62 & 3.26 & .76 \\
\hline 14. & $\begin{array}{l}\text { I get restless if I don't exercise } \\
\text { regularly }\end{array}$ & 3.53 & 1.26 & -0.54 & -0.75 & .64 \\
\hline \multicolumn{7}{|l|}{$\begin{array}{l}\text { Intrinsic regulation } \\
\quad(\text { Cronbach's } \alpha=.91)\end{array}$} \\
\hline 4. & I exercise because it's fun & 3.89 & 1.04 & -0.89 & 0.31 & .83 \\
\hline 8. & I enjoy my exercise sessions & 4.25 & 0.87 & -1.28 & 1.77 & .84 \\
\hline 12. & $\begin{array}{l}\text { I find exercise a pleasurable } \\
\text { activity }\end{array}$ & 4.10 & 0.92 & -0.97 & 0.69 & .94 \\
\hline 15. & $\begin{array}{l}\text { I get pleasure and satisfaction from } \\
\text { exercise }\end{array}$ & 4.37 & 0.85 & -1.48 & 2.18 & .85 \\
\hline Interfactor correlations & & 1. & 2. & 3. & 4. & \\
\hline 1. & External Regulation & - & & & & \\
\hline 2. & Introjected Regulation & .19 & - & & & \\
\hline 3. & Identified Regulation & -.24 & .41 & - & & \\
\hline 4. & Intrinsic Regulation & -.24 & .14 & .78 & - & \\
\hline
\end{tabular}

Note. $\mathrm{CFA}=$ confirmatory factor analysis; $\mathrm{BREQ}=$ Behavioral Regulation in Exercise Questionnaire. 
Item 9: "Because others will not be pleased with me if I don't") exhibited a pattern of large (> $>2.00$; Byrne, 1994) standardized residuals. The modification indexes suggested that model fit could be substantially improved if Item 9 was allowed to crossload on the introjected factor; however, this pattern of loadings could not be theoretically justified. Internal consistency estimates (see Table 1) indicated that all BREQ subscales demonstrated acceptable reliability.

Simplex model analysis. Following the procedures outlined by $\mathrm{Li}$ and Harmer (1996), we specified and tested a simplex model for the BREQ by using Arbuckle's (1997) AMOS program. In this analysis, the simplex model consisted of four latent factors (each underpinned by their relevant measured variables from the CFA) connected by direct paths between adjacent motivational constructs. Maximum likelihood estimation procedures were used to test the fit of the covariance matrix to the specified model. The overall fit of the model was tenable $(\mathrm{Q}=4.03, \mathrm{NFI}=.87, \mathrm{IFI}=.90, \mathrm{CFI}=.90, \mathrm{SRMSR}=.09, \mathrm{RMSEA}=.09,90 \% \mathrm{CI}=$ $.08-.10$ ), and the magnitude of the direct versus indirect paths (see Table 2) supported the presence of a simplex structure underlying BREQ responses. ${ }^{4}$

Nomological net. The relations between the BREQ and both psychological need satisfaction variables and exercise behavior (see Tables 3 and 4) supported the major tenets of SDT. Consistent with our original hypotheses, perceived competence, autonomy, and relatedness were more positively correlated with identified and intrinsic regulations than with introjected or external regulations. The correlations between perceived relatedness and exercise regulations were quite weak in overall magnitude compared with those exhibited by both perceived competence and autonomy. In terms of motivational consequences, more self-determined exercise motives in the form of identified and intrinsic regulation exhibited stronger and more positive relations with exercise behavior.

\footnotetext{
${ }^{4}$ Both the CFA and SEM analyses were recomputed after the removal of Item 9. Not surprisingly, the overall fit of the four-factor measurement model $(\mathrm{Q}=3.12, \mathrm{NFI}=.93, \mathrm{IFI}=.95, \mathrm{CFI}=.95, \mathrm{SRMSR}=$ $.04, \mathrm{RMSEA}=.07,90 \% \mathrm{CI}=.06-.08)$ and the structural model $(\mathrm{Q}=4.11, \mathrm{NFI}=.92, \mathrm{IFI}=.94, \mathrm{CFI}=.94$, $\mathrm{SRMSR}=.09, \mathrm{RMSEA}=.08,90 \% \mathrm{CI}=.07-.09)$ improved. However, given the aberrant distributional properties exhibited by Item 9 in this sample of exercise participants and the likelihood of capitalizing on chance relations when relying on model modification indices alone, we believed it would be imprudent to remove this item from the BREQ until further research is conducted. Consequently, the results of these additional analyses should be interpreted with a suitable degree of circumspection.
} 
TABLE 2

Parameter Estimates for Simplex Model Pathways Underpinning the BREQ

\begin{tabular}{lc}
\hline Relationship Paths & $\begin{array}{c}\text { Standardized } \\
\text { Estimates }\end{array}$ \\
\hline Direct effects & \\
External regulation $\rightarrow$ introjected regulation & .18 \\
Introjected regulation $\rightarrow$ identified regulation & .28 \\
Identified regulation $\rightarrow$ intrinsic regulation & .75 \\
Indirect effects & .05 \\
External regulation $\rightarrow$ introjected regulation $\rightarrow$ identified regulation & .04 \\
External regulation $\rightarrow$ introjected regulation $\rightarrow$ identified regulation $\rightarrow$ intrinsic regulation & .21 \\
Introjected regulation $\rightarrow$ identified regulation $\rightarrow$ intrinsic regulation & .04 \\
\hline
\end{tabular}

Note. $\mathrm{BREQ}=$ Behavioral Regulation in Exercise Questionnaire.

\section{Summary}

The purpose of Phase 1 was to test the measurement and structural properties underpinning the BREQ and examine the relations between BREQ subscales and both psychological need satisfaction and exercise behavior. The findings of Phase 1 support the latent factor and simplex structure of the BREQ, the internal consistency of the items comprising BREQ subscales, and a pattern of relations between BREQ subscales, psychological need satisfaction, and exercise behavior that are consistent with SDT (Deci \& Ryan, 1985; Ryan \& Deci, 2000). The notion of a simplex structure is central to the SDT proposition that motivation resides along a continuum of psychological need satisfaction such that adjacent constructs are more strongly related to one another compared with distal constructs. In this regard, it is encouraging to see the BREQ display qualities that are consistent with a central proposition of the theory. Collectively, these results further support the psychometric properties of the BREQ and suggest that the scale measures exercise motivation in line with the major propositions of SDT.

Three additional points of interest emerged from Phase 1. First, the construct of perceived relatedness appears to have weaker relations with self-determined exercise motives than either perceived competence or autonomy. Although not originally hypothesized, this finding is consistent with SDT given that relatedness "provides the groundwork for facilitating internalization" (Ryan \& Deci, 2000, p. 64); however, in the absence of autonomy, perceived relatedness may simply underpin the development of controlling motives such as introjection. Second, identified regulation appears to be the most prominent source of extrinsic motivation associated with more frequent patterns of exercise behavior. Finally, introjected regulation was positively related to strenuous exercise pat- 
TABLE 3

Relationships Between BREQ Subscales and Psychological Needs Satisfaction Constructs

\begin{tabular}{|c|c|c|c|c|c|c|c|c|c|c|}
\hline Variables & $M$ & $S D$ & Skewness & 1 & 2 & 3 & 4 & 5 & 6 & 7 \\
\hline 1. External regulation & 1.39 & 0.59 & 2.07 & - & & & & & & \\
\hline 2. Introjected regulation & 2.53 & 0.95 & 0.41 & $.21 * * *$ & - & & & & & \\
\hline 3. Identified regulation & 4.26 & 0.72 & -1.25 & $-.22 * * *$ & $.31 * * *$ & - & & & & \\
\hline 4. Intrinsic regulation & 4.26 & 0.75 & -1.25 & $-.20 * * *$ & $.10^{* *}$ & $.68 * * *$ & - & & & \\
\hline 5. Competence & 5.50 & 1.07 & -0.62 & $-.18 * * *$ & .06 & $.37 * * *$ & $.46^{* * * *}$ & - & & \\
\hline 6. Autonomy & 5.56 & 1.19 & -0.86 & -.07 & $.12 * *$ & $.37 * * *$ & $.40 * * *$ & $.49 * * *$ & - & \\
\hline 7. Relatedness & 4.56 & 1.48 & -0.36 & .02 & $.12 * *$ & $.16^{* * * *}$ & $.19 * * *$ & $.23 * * *$ & $.27 * * *$ & - \\
\hline
\end{tabular}

Note. All Kurtosis values for psychological need satisfaction variables were within acceptable limits in this sample (Competence $=0.621$; Autonomy =0.971; Relatedness $=-0.234)$. BREQ = Behavioral Regulation in Exercise Questionnaire . $* p<.10$. ** $p<.05$. *** $p<.001$. 
TABLE 4

Relationships Between BREQ Subscales and Patterns of Self-Reported Exercise Behavior

\begin{tabular}{lccc}
\hline Variables & Mild Exercise & Moderate Exercise & Strenuous Exercise \\
\hline External regulation & $-.15^{*}$ & $-.17^{* *}$ & -.11 \\
Introjected regulation & .01 & -.01 & $.31^{* * *}$ \\
Identified regulation & $.18^{* *}$ & $.33^{* * *}$ & $.45^{* * *}$ \\
Intrinsic regulation & .11 & $.19^{* *}$ & $.35^{* * *}$ \\
\hline
\end{tabular}

Note. $\mathrm{BREQ}=$ Behavioral Regulation in Exercise Questionnaire.

$* p<.10 . * * p<.05 . * * * p<.001$.

terns, suggesting that feelings of obligation and compulsion can represent a powerful force motivating exercise behavior.

\section{PHASE 2}

The purpose of Phase 2 was to extend the construct validity evidence for the BREQ by examining relations between BREQ subscales and motivational constructs relevant to the promotion of exercise behavior. Previous exercise psychology researchers have linked both perceived behavioral control and optimism with greater exercise participation (Courneya et al., 1998; Kavussanu \& McAuley, 1995). Given that SDT proposes that self-determined regulations positively influence motivational consequences, it seems reasonable to suggest that psychological variables that have been positively linked with exercise behavior should be favorably related to more self-determined exercise regulations as measured by the BREQ. Consequently, we hypothesized that identified and intrinsic regulations would be more positively correlated with optimism and perceived behavioral control than either introjected or external regulations.

\section{Method}

Participants $(N=51,76.8 \%$ female; males' mean age $=42.85, S D=10.77$; females' mean age $=41.47, S D=10.84)$ in this phase were community residents enrolled in a study examining the psychological and physiological correlates associated with exercising at different intensity levels. Demographic data suggested that these participants were slightly older than Phase 1 participants $(M=41.75, S D=10.75)$ and had body mass index values $\left(M=27.6 \mathrm{~kg} / \mathrm{m}^{2}, S D=5.41 \mathrm{~kg} / \mathrm{m}^{2}\right)$ that exceeded the desired healthy range for adults (Kerney, 1995). All Phase 2 participants were enrolled in a 12-week supervised exercise program that was designed to improve aerobic fitness in accordance with current guidelines (Pollock et al., 1998). After obtaining informed consent, participants completed a series of questionnaires indi- 
vidually while attending an orientation session designed to explain the project and collect anthropometric data.

\section{Measures}

BREQ. All participants completed the same 15-item BREQ (Mullen et al., 1997) described in Phase 1 of this study.

Life Orientation Test (LOT). Participants completed the LOT (Scheier \& Carver, 1985) as a measure of dispositional optimism. The LOT is a 12-item measure that has been used in previous health psychology research examining predictors of exercise adherence (Hamid, 1990). Participants rated their agreement with each item on a 5-point Likert scale ranging from 0 (strongly disagree) to 4 (strongly agree). Previous researchers have suggested that the LOT is a reliable indicator of optimism (Cronbach's $\alpha=.78-.82$; Scheier, Carver, \& Bridges, 1994) and that dispositional optimism predicts more persistent exercise behavior patterns (Hamid, 1990; Kavussanu \& McAuley, 1995). The items were averaged to create an overall score such that a higher score indicated greater optimism.

Perceived behavioral control (PBC). PBC was assessed by using three items developed specifically within the physical activity domain for use in exercise psychology research (Courneya \& McAuley, 1995; Courneya et al., 1998). PBC refers to the degree of ease or difficulty associated with controlling exercise behavior (sample item $=$ "For me to exercise regularly over the next 4 months is easy/difficult"). Participants rate their agreement with each item on a 9-point Likert scale ranging from 1 (easy) to 9 (difficult). Previous researchers have suggested that these items demonstrate adequate reliability (Cronbach's $\alpha=.80$; Courneya \& McAuley, 1995) and a pattern of positive relations with both exercise intentions and behavior (Courneya et al., 1998). The items were averaged to create an overall PBC score such that a lower score indicated greater perceptions of control over exercise.

\section{Data Analysis}

Data analysis proceeded in three stages. First, internal consistency estimates (Cronbach's coefficient $\alpha$ ) were computed for all variables. Second, subscales were formed and relevant descriptive statistics were calculated. Finally, Pearson correlations were computed between the BREQ subscales, PBC, and optimism. 


\section{Results}

Scale reliability. Reliability analyses (Cronbach's coefficient $\alpha$ ) indicated that all scales demonstrated acceptable levels of internal consistency (see Table 5) and the removal of any item would not have improved the overall reliability of any measure.

Descriptive statistics. The descriptive statistics indicated that identified regulation was the most strongly endorsed motive for exercise involvement, followed closely by intrinsic regulation. The values for external and introjected regulation were somewhat lower in these participants, suggesting that perceived pressure to exercise represents a less salient source of exercise motivation in this sample. These participants reported similar endorsement of external and introjected regulation but slightly lower identified and intrinsic regulation scores compared with Phase 1 participants.

Construct validity. Bivariate correlations were computed between the four BREQ subscales, optimism, and PBC. The results (Table 5) partially support our original hypotheses, with more self-determined exercise regulations being more positively related to optimism and $\mathrm{PBC}$; however, the relations between exercise regulations and optimism are somewhat weaker than those exhibited between BREQ subscales and PBC.

\section{Summary}

The purpose of Phase 2 was to extend the construct validity evidence of the BREQ by linking responses on this scale with other motivational constructs previously

TABLE 5

Relationships Between BREQ Subscales, Optimism, and Perceived Behavioral Control

\begin{tabular}{lcccccccc}
\hline Variables & $M$ & $S D$ & 1 & 2 & 3 & 4 & 5 & 6 \\
\hline External regulation & 1.53 & 0.73 & $(.84)$ & & & & & \\
Introjected regulation & 2.34 & 0.75 & .20 & $(.83)$ & & & & \\
Identified regulation & 3.66 & 0.79 & -.16 & .22 & $(.70)$ & & & \\
Intrinsic regulation & 3.32 & 0.98 & -.20 & .06 & $.68^{* * *}$ & $(.92)$ & & \\
Optimism & 2.68 & 0.63 & -.12 & $-.25^{*}$ & $.23^{*}$ & .20 & $(.84)$ & \\
Perceived behavioral control & 3.60 & 1.69 & -.22 & -.18 & $.43^{* * *}$ & $.34^{* *}$ & $.43^{* * *}$ & $(.83)$ \\
\hline
\end{tabular}

Note. Reliability estimates (Cronbach's $\alpha$ ) are placed along the principal diagonal $(N=51)$. BREQ $=$ Behavioral Regulation of Exercise Questionnaire.

$* p<.10 . * * p<.05 . * * * p<.001$. 
demonstrated to positively influence exercise behavior. In general, the results of these analyses further support the psychometric integrity of the BREQ as a multidimensional measure of exercise motivation. In addition, the results provide some support for SDT given the positive relations exhibited between more self-determined regulations (intrinsic and identified) and $\mathrm{PBC}$. Although the relations with optimism were consistent with theoretical predictions, the overall magnitude of these relations was weak at best.

\section{GENERAL DISCUSSION}

This study was designed to extend the construct validity evidence associated with the BREQ to determine the suitability of the scale for examining the propositions of SDT in the exercise domain. The results of this study render some support for the psychometric merit of the scale given (a) the ability of the BREQ to account for the observed data in both CFA and SEM analyses, (b) the demonstration of adequate reliability across two samples, and (c) the pattern of relations exhibited between the BREQ subscales and psychological need satisfaction constructs, exercise behavior, and $\mathrm{PBC}$ that are consistent with theoretical propositions. Collectively, these results further support the psychometric properties of the BREQ and, together with previous research (Mullen et al., 1997), suggest that the scale may be useful for examining propositions put forth within the framework of SDT (Deci \& Ryan, 1985; Ryan \& Deci, 2000).

\section{BREQ Factor Structure and Composition}

The results from the CFA support the multidimensional four-factor structure of the BREQ proposed by Mullen et al. (1997) and advocated more broadly within SDT (Deci \& Ryan 1985; Ryan \& Deci, 2000). In addition to the adequate fit of the measurement model, the overall fit of the structural model observed in the SEM analyses supported the presence of a simplex structure underlying BREQ responses in this sample of exercise participants. Given that a simplex structure positing stronger positive relations between adjacent constructs along the motivational continuum is a major proposition of SDT (Ryan \& Deci, 2000), it is particularly encouraging to see that the BREQ demonstrates properties in line with this theoretical postulate. Consistent with calls for repeated assessment of scale dimensionality (Messick, 1995), our findings both support and extend previous evidence of the validity of the BREQ in two ways. First, we examined and supported the dimensionality of the scale in a sample of exercise participants who differed from those studied previously (Mullen \& Markland, 1997; Mullen et al., 1997). Second, we tested and supported the presence of a simplex structure underlying BREQ re- 
sponses by using SEM procedures advocated by Li and Harmer (1996). Given these encouraging findings, researchers should address the generalizability of these results in more diverse samples (e.g., males, older adults) and contexts (e.g., rehabilitation clinics) where exercise adherence is an important research priority.

Two additional points of interest emerged from the CFA and SEM analyses. First, the standardized residuals and modification indexes suggested that Item 9 may be somewhat problematic. This is consistent with the findings of Mullen et al. (1997), who reported that the same item demonstrated the lowest standardized factor loading (0.56) compared with the other items comprising the BREQ in their sample of community fitness center users. Possibly, this item taps feelings of external evaluation that are somewhat distinct from perceived social coercion, that appears to be represented by the content of the other external regulation items. This interpretation should be tempered with caution given the nonnormal distribution exhibited by Item 9 in this sample and the tendency for maximum likelihood estimators to underestimate both global model fit and specific parameter estimates under such conditions. If researchers continue to identify Item 9 as problematic, it may be worth modifying the wording to heighten the salience of external control expressed by the content of this item.

The second point of interest emerging from the CFA analysis in this study was the high interfactor correlation exhibited between the identified and intrinsic exercise regulation subscales. Specifically, the interfactor correlation (Table 1) between these adjacent points on the BREQ continuum suggests that these subscales shared approximately $61 \%$ common variance. This substantive overlap is slightly less than the interfactor correlation reported by Mullen et al. (1997) in the original development of the BREQ (interfactor $r=.84$ ), but it highlights a potential problem when the BREQ is used in predictive analyses. Given the strong relations between these two constructs, important relations with other variables may be masked due to collinearity effects between identified and intrinsic regulation as measured by the BREQ. Thus, researchers using the BREQ in predictive analyses should be cognizant of the high degree of overlap between these subscales and should attempt to determine the unique variance accounted for in the criterion variable under investigation by both identified and intrinsic regulations.

\section{Construct Validity of the BREQ}

The pattern of relations exhibited between the BREQ subscales and psychological need satisfaction constructs proposed within SDT further supported the construct validity of the BREQ. According to SDT (Deci \& Ryan, 1985; Ryan \& Deci, 2000), identified and intrinsic regulations develop in contexts that facilitate the satisfaction of basic psychological needs for competence, autonomy, and relatedness. In this study, perceived competence and autonomy demonstrated a discernibly stronger pattern of relations with identified and intrinsic regulations; 
however, perceived relatedness was less distinctly associated with self-determined exercise regulations.

Although not originally hypothesized, this finding supports recent theorizing which suggests that perceived relatedness may be a catalyst responsible for the internalization of behavioral regulation, especially when the task itself is not perceived to be intrinsically motivating (Ryan \& Deci, 2000). Ryan and Deci cautioned that in the absence of autonomy, the internalization process may regulate behavior by controlling introjects that conceptually represent minimal degrees of self-determination. In other words, perceptions of relatedness in conjunction with perceived autonomy are more likely to facilitate forms of regulation that are fully integrated with the self. Researchers may wish to examine this issue more carefully by manipulating environmental characteristics (e.g., exercising alone or with others) to determine the impact of enhancing perceived relatedness on motivational development in the exercise domain.

The results of this study highlight an interesting pattern of relations between the SDT motivational continuum and exercise behavior, which has important motivational implications from a health promotion standpoint. According to SDT, regulations underpinned by greater self-determination nurture positive motivational consequences such as task persistence and enhanced psychological well-being (Deci \& Ryan, 1985; Ryan \& Deci, 2000). The results of Phase 1 indicate that identified and intrinsic regulations were favorably associated with more frequent exercise behavior patterns, and this pattern was strongest for identified regulation. This finding supports research from other domains that has linked identified regulation with more positive motivational outcomes such as behavioral investment (Koestner, Losier, Vallerand, \& Carducci, 1996), and it points to the importance of understanding why identified regulation appears to be associated with "adaptive" motivational consequences. Vallerand (1997) contended that identified regulation may be the most important predictor of motivational consequences when the nature of the task is not interesting or self-rewarding. Researchers may wish to examine this issue more thoroughly by assessing the long-term implications for adherence and psychological well-being of endorsing identified versus intrinsic regulation in the exercise domain.

The findings of this study are consistent with both previous research (Koestner et al., 1996; Vallerand, 1999) and theory (Deci \& Ryan, 1985; Ryan \& Deci, 2000), and the findings suggest that measuring motivation in line with the SDT propositions more fully illuminates the role played by different exercise motives underpinning exercise behavior. Collectively, this pattern of findings between the constructs measured by the BREQ and the proposed psychological foundations and behavioral consequences of self-determined exercise motives lends some credence to the "meaningfulness" (Messick, 1995) that can be ascribed to BREQ scores. Although these findings support theoretical propositions, the relations observed in this study were cross-sectional in nature and offer minimal insight into 
the causal relations among the constructs of SDT. Given that SDT (Deci \& Ryan, 1985; Ryan \& Deci, 2000) proposes a temporal relation between need satisfaction, behavioral regulation, and motivational consequences, researchers should consider using longitudinal designs to test the temporal sequence of relations among SDT's constructs.

\section{Relations With Motivational Constructs}

Our study extends previous research pertaining to the BREQ by highlighting the relation between the scale and motivational constructs previously acknowledged to play an influential role in exercise adherence (Courneya et al., 1998; Hamid, 1990; Kavussanu \& McAuley, 1995). According to SDT (Deci \& Ryan, 1985; Ryan \& Deci, 2000), more self-determined motives in the form of identified and intrinsic regulations should be most favorably associated with positive motivational consequences. Researchers have supported the robust link between greater perceptions of behavioral control and exercise adherence (Courneya et al.). Therefore, it seems reasonable to suggest that more self-determined exercise regulations should be favorably related to other motivational constructs that have been shown to positively influence both exercise intentions and behavior. Our findings partially support this hypothesis given the positive relations observed between PBC and both identified and intrinsic exercise regulation. Researchers may wish to extend these findings by examining the links between the subscales and a broader array of reasons responsible for exercise involvement such as health, fitness, and affiliation motives.

Our findings marginally supported the hypothesis regarding the relation between exercise regulations and optimism. One possible explanation for these weak findings can be offered by considering the conceptual relations between variables at different levels in the hierarchical model of motivation proposed by Vallerand (1997). Consistent with this model, variables exist at either a global, contextual, or situational level of influence, and the relations between variables residing at different levels should be weaker than those that operate at the same conceptual level. Given that the BREQ is a contextual measure of exercise motivation, it seems reasonable to suggest that the scale would be strongly related only with other contextual measures such as psychological need satisfaction in exercise contexts and exercise behavior. Indeed, our results from Phase 1 of this study along with previous research in the sport domain (Kowal \& Fortier, 2000) support such a proposition. However, optimism as measured by the LOT is a dispositional variable that is conceptually analogous to personality dimensions, which, according to the Vallerand model, reside at the global level and should be less strongly related to constructs measured at any other level. Researchers could address this issue more carefully in the exercise domain by testing the interrelations between constructs at multiple levels proposed by Vallerand. 
The purpose of this study was to examine and extend the psychometric properties of BREQ to determine the utility of this scale for measuring exercise motivation within the framework of SDT (Deci \& Ryan, 1985; Ryan \& Deci, 2000). In general, the results support the psychometric properties of the BREQ in terms of the factorial validity evidence and the relations with theoretically relevant constructs, exercise behavior, and motivational constructs previously associated with greater behavioral persistence in the exercise domain. Collectively, these findings support the meaningfulness of the inferences that can be drawn from scores on the BREQ (Messick, 1995) and support the measurement of exercise motivation from a multidimensional perspective (Vallerand \& Fortier, 1998). In addition, the results of this study lend some credence to examining motivational issues within the exercise domain from a self-determination perspective. Consequently, future research using SDT as a guiding theoretical framework and using the BREQ appears warranted.

\section{ACKNOWLEDGMENTS}

Funding for this study was provided through a grant awarded to Wendy Rodgers by the Social Sciences and Humanities Research Council of Canada.

We are grateful to the helpful comments provided by three anonymous reviewers and Barbara E. Jensen (co-editor) during the review process that substantially improved the quality of this article.

\section{REFERENCES}

Arbuckle, J. L. (1997). AMOS: Version 3.6 [Computer software]. Chicago: Smallwaters.

Byrne, B. M. (1994). Structural equation modeling with EQS and EQS/Windows: Basic concepts, applications, \& programming. Thousand Oaks, CA: Sage.

Courneya, K. S., \& McAuley, E. (1995). Cognitive mediators of the social influence-exercise adherence relationship: A test of the theory of planned behavior. Journal of Behavioral Medicine, 18, 499-515.

Courneya, K. S., Nigg, C., \& Estabrooks, P. (1998). Relationships among the theory of planned behavior, stages of change and exercise behavior in older persons over a three year period. Psychology \& Health, 13, 355-367.

Cronbach, L. J. (1951). Coefficient alpha and the internal structure of tests. Psychometrika, 16, 297234.

Cronbach, L. J., \& Meehl, P. E. (1955). Construct validity in psychological tests. Psychological Bulletin, 52, 281-302.

Deci, E. L., \& Ryan, R. M. (1985). Intrinsic motivation and self-determination in human behavior. New York: Plenum.

Dishman, R. K.(1994). Exercise adherence: Its impacton public health. Champaign, IL:Human Kinetics. 
Gardner, D. G., Cummings, L. L., Dunham, R. B., \& Pierce, J. L. (1998). Single-item versus multiple-item measurement scales: An empirical example. Educational \& Psychological Measurement, 58, 898-906.

Godin, G., \& Shepherd, R. (1985). A simple method to assess exercise behavior in the community. Canadian Journal of Applied Sport Science, 10, 141-146.

Hamid, P. N. (1990). Optimism and the reporting of flu episodes. Social Behavior \& Personality, 18, 225-234.

Hoyle, R. H., \& Panter, A. T. (1995). Writing about structural equation models: In R. Hoyle (Ed.), Structural equation modeling: Concepts, issues, and applications (pp. 158-176). Thousand Oaks, CA: Sage.

Hu, L., \& Bentler, P. M. (1995). Evaluating model fit. In R. Hoyle (Ed.), Structural equation modeling: Concepts, issues, and applications (pp. 76-99). Thousand Oaks, CA: Sage.

Jacobs, D. R., Ainsworth, B. E., Hartman, T. J., \& Leon, A. S. (1993). A simultaneous evaluation of 10 commonly used physical activity questionnaires. Medicine \& Science in Sports \& Exercise, 25, 81-91.

Kavussanu, M., \& McAuley, E. (1995). Exercise and optimism: Are highly active individuals more optimistic? Journal of Sport \& Exercise Psychology, 17, 246-258.

Kelloway, E. K. (1998). Using LISREL for structural equation modeling - A researcher's guide. Thousand Oaks, CA: Sage.

Kerney, W. (1995). American college of sports medicine's guidelines for exercise testing and prescription. Baltimore: Williams \& Wilkins.

Koestner, R., Losier, G. F., Vallerand, R., \& Carducci, D. (1996). Identified and introjected forms of political internalization: Extending self-determination theory. Journal of Personality \& Social Psychology, 70, 1025-1036.

Kowal, J., \& Fortier, M. S. (2000). Testing relationships from the hierarchical model of intrinsic and extrinsic motivation using flow as a motivational consequence. Research Quarterly for Exercise \& Sport, 71, 171-181.

Li, F. (1999). The exercise motivation scale: Its multifaceted structure and construct validity. Journal of Applied Sport Psychology, 11, 97-115.

Li, F., \& Harmer, P. (1996). Testing the simplex assumptions underlying the sport motivation scale: A structural equation modeling analysis. Research Quarterly for Exercise \& Sport, 67, 396-405.

Losier, G. F., Bourque, P. E., \& Vallerand, R. J. (1993). A motivational model of leisure participation in the elderly. Journal of Psychology, 127, 153-170.

Losier, G. F., \& Koestner, R. (1999). Intrinsic versus identified regulation in distinct political campaigns: The consequences of following politics for pleasure versus personal meaningfulness. Personality \& Social Psychology Bulletin, 25, 287-298.

Maruyama, G. M. (1998). Basics of structural equation modeling. Thousand Oaks, CA: Sage.

Messick, S. (1995). Validity of psychological assessment: Validation of inferences from persons' responses and performances as scientific inquiry into score meaning. American Psychologist, 50, 741-749.

Mullen, E., \& Markland, D. (1997). Variations in self-determination across the stages of change for exercise in adults. Motivation \& Emotion, 21, 349-362.

Mullen, E., Markland, D., \& Ingledew, D. K. (1997). A graded conceptualization of self-determination in the regulation of exercise behavior: Development of a measure using confirmatory factor analysis procedures. Personality \& Individual Differences, 23, 745-752.

Pelletier, L. G., Fortier, M. S., Vallerand, R. J., Tuson, K. M., Briere, N. M., \& Blais, M. R. (1995). Toward a new measure of intrinsic motivation, extrinsic motivation, and amotivation in sports: The sport motivation scale. Journal of Sport \& Exercise Psychology, 17, 35-53.

Pollock, M. L., Gaesser, G. A., Butcher, J. D., Despres, J. P., Dishman, R. K., Franklin, B. A., \& Ewing Garber, C. (1998). The recommended quantity and quality of exercise for developing and maintaining cardiorespiratory and muscular fitness, and flexibility in healthy adults. Medicine \& Science in Sports \& Exercise, 30, 975-991. 
Ryan, R. M., \& Deci, E. L. (2000). Intrinsic and extrinsic motivations: Classic definitions and new directions. Contemporary Educational Psychology, 25, 54-67.

Scheier, M. F., \& Carver, C. (1985). Optimism, coping, and health: Assessment and implications of generalized outcome expectancies. Health Psychology, 4, 219-247.

Scheier, M. F., Carver, C., \& Bridges, M. W. (1994). Distinguishing optimism from neuroticism (and trait anxiety, self-mastery, and self-esteem): A reevaluation of the Life Orientation Test. Journal of Personality \& Social Psychology, 67, 1063-1078.

Sheldon, K. M., \& Elliot, A. J. (1999). Goal striving, need satisfaction, and psychological well-being: The self-concordance model. Journal of Personality \& Social Psychology, 76, 482-497.

Thompson, B. (2000). Ten commandments of structural equation modeling. In L. G. Grimm \& P. R. Yarnold (Eds.), Reading and understanding more multivariate statistics (pp. 261-285). Washington, DC: American Psychological Association.

Vallerand, R. J. (1997). Toward a hierarchical model of intrinsic and extrinsic motivation. In M. P. Zanna (Ed.), Advances in experimental social psychology (pp. 271-360). San Diego, CA: Academic.

Vallerand, R. J. (1999). Intrinsic and extrinsic motivation in sport: Toward a hierarchical model. In R. Lidor \& M. Bar-Eli (Eds.), Sport psychology: Linking theory to practice (pp. 191-212). Morgantown, WV: Fitness Information Technology.

Vallerand, R. J., \& Fortier, M. (1998). Measures of intrinsic and extrinsic motivation in sport and physical activity: A review and critique. In J. Duda (Ed.), Advances in sport \& exercise psychology measurement (pp. 81-101). Morgantown, WV: Fitness Information Technology.

Vallerand, R. J., Fortier, M. S., \& Guay, F. (1997). Self-determination and persistence in a real life setting: Toward a motivational model of high school dropout. Journal of Personality \& Social Psychology, 72, 1161-1176.

West, S. G., Finch, J. F., \& Curran, P. J. (1995). Structural equation models with nonnormal variables: Problems and remedies. In R. H. Hoyle (Ed.), Structural equation modeling: Concepts, issues, and applications (pp. 56-75). Thousand Oaks, CA: Sage.

Williams, G., Freedman, Z. R., \& Deci, E. L. (1998). Supporting autonomy to motivate patients with diabetes for glucose control. Diabetes Care, 21, 1644-1651. 
Copyright of Measurement in Physical Education \& Exercise Science is the property of Lawrence Erlbaum Associates and its content may not be copied or emailed to multiple sites or posted to a listserv without the copyright holder's express written permission. However, users may print, download, or email articles for individual use. 